\title{
Short term outcome in babies refused perinatal intensive care
}

\author{
Harmini Sidhu, Richard N Heasley, Christopher C Patterson, Henry L Halliday, William Thompson
}

\begin{abstract}
Objective-To compare the mortality in babies refused admission to a regional perinatal centre with that in babies accepted for intensive care in the centre.

Design-Retrospective study with group comparison.

Setting-Based at the Royal Maternity Hospital, Belfast, with follow up of patients in all obstetric units in Northern Ireland.
\end{abstract}

Patients-Requests for transfer of 675 babies to the regional perinatal centre (prenatally and postnatally) were made from hospitals in Northern Ireland between January 1984 and December 1986. In all, 343 babies were refused admission to the centre, and complete data were available for 332 of them. These babies were either admitted to other neonatal intensive care units ( 261 babies) or remained in hospitals with only special care cots (71 babies).

Main outcome measure-Short term mortality.

Results - Seventy of the 332 babies refused admission to the centre died compared with 51 of the 333 who were admitted. Multivariate analysis based on a logistic model showed a non-significant increase in mortality among babies treated in other intensive care units compared with babies treated in the centre (relative odds $1.2 ; 95 \%$ confidence interval 0.7 to 1.9). The increase in mortality in babies who remained in a special care baby unit, however, was significant $(3.5 ; 1.7$ to 7.0$)$. This increase was particularly significant in babies born at $\leqslant 32$ weeks' gestation and who weighed less than $1500 \mathrm{~g}(8 \cdot 4 ; 2.5$. to $28 \cdot 1$ ).

Conclusions - The results of the study confirm the benefits of neonatal intensive care and its particular value in improving survival in babies of low birth weight. As the babies were refused admission to the regional perinatal centre because intensive care cots were not available this deficiency should be corrected.

\section{Introduction}

Several studies have investigated outcome in babies of low birth weight after transfer either prenatally or postnatally to a regional neonatal intensive care unit and compared it with that in babies born outside the regional centres. ${ }^{1-3}$ Although such comparisons seem to justify transfer, confounding variables must be taken into account in the statistical analysis. ${ }^{+} \mathrm{A}$ working party of the Royal College of Physicians recently reported a national shortage of intensive care cots. 'As a result of this shortage obstetricians and paediatricians in district maternity units may be unable to secure the admission of all babies to intensive care units. It is therefore imperative to compare survival in babies after transfer with that in babies for whom transfer was requested but refused because of lack of facilities in the regional unit. To date there have been two such studies both restricted to transfer of babies postnatally, which suggested that mortality in infants who are refused transfer is higher than that in those who are transferred. ${ }^{6 i}$ We studied babies who were referred pre- natally or postnatally and refused admission to a regional perinatal centre over three years.

\section{Patients and methods}

Northern Ireland is the size of a small regional health authority and has 25 maternity hospitals for 28000 births each year. Some of these hospitals have special care cots but no resident paediatric staff and only visiting consultants; these are designated special care baby units. Other paediatric units in district general hospitals have consultant paediatricians and resident paediatric staff. There are six such units, and each has facilities for two intensive care cots: these units are called neonatal intensive care units. Requests for transfer to the regional perinatal centre at the Royal Maternity Hospital, Belfast, come from all hospitals in the region.

About 4000 babies are born at the hospital each year, a large proportion of whom are at high risk. Babies at high risk are referred, either prenatally or postnatally, to the hospital from all over Northern Ireland for specialised perinatal care. During the study the regional perinatal centre had a consultant perinatologist, three consultant neonatologists, and resident junior staff; there were four intensive care cots and four high dependency cots. In addition, there was ready access to regional specialties such as paediatric cardiology, surgery, and neurosurgery.

Since 1984 all requests for transfer to the regional centre have been recorded in a log book. If a request was refused the surname, gestational age, and the type of transfer request (prenatal or neonatal) were noted. Babies initially refused transfer but subsequently transferred were coded as acceptances, despite delays of up to four weeks. With this information the case notes of every patient refused transfer between January 1984 and December 1986 were traced by one of us (HS), who visited each of the hospitals that referred the patients.

We recorded data relating to the antenatal period, delivery, and outcome in terms of survival of the neonate on a form. If patients were transferred to one of the six units with intensive care facilities other than the regional centre this was also recorded and the case notes traced. Thus patients who were refused transfer to the centre were divided into two groups: those who remained in hospitals without any facilities for intensive care in special care baby units and those who eventually received intensive care in smaller neonatal intensive care units.

The characteristics of babies in these two groups and of those who were transferred to the centre were compared by $\chi^{2}$ tests for categorical variables and one way analyses of variance for continuous variables. A multivariate analysis based on a logistic model was used to compare the survival in the three groups ${ }^{*}$; this was adjusted for imbalance in the distribution among the groups of important obstetric and perinatal variables. The logistic model assumes that the logarithm of the odds on death may be expressed as a linear combination of covariates. The covariates considered were birth weight, gestational age, the presence or absence of the respiratory distress syndrome at birth, 
cephalic or breech presentation, Apgar scores at 1 and 5 minutes, multiple pregnancy, and whether or not the request for transfer was made before birth. This list included all the factors that Patterson and Halliday found to be related independently to the risk of death in babies born before term. ${ }^{9}$ These factors were either considered as continuous variables or coded as a series of binary variables. Models were fitted with the generalised linear interactive model (GLIM) package. From the coefficients representing the comparison of groups we could estimate the odds on death in the two groups of patients refused admission to the centre relative to those accepted and obtain $95 \%$ confidence intervals for these relative odds.

\section{Results}

During the study there were 675 requests for transfer to the regional centre, 343 of which were refused because intensive care cots were not available. Complete data were obtained for 332 of the babies refused transfer and for all of those accepted for transfer. Seven of the 11 missing charts were from a small urban delivery unit where records were difficult to trace. Of the 332 babies who were refused transfer and for whom complete data were obtained, 261 remained in or were subsequently admitted to other intensive care units, while 71 remained in hospitals that had only special care cots. The most common reasons for requesting transfer prenatally were preterm labour (including preterm rupture of membranes) and pre-eclampsia. Low birth weight and its associated

TABLE I-Main reasons for requests for transfer of babies to regional perinatal centre prenatally or neonatally according to whether babies were treated at centre, in neonatal intensive care unit, or in special care baby unit

\begin{tabular}{|c|c|c|c|}
\hline Reason for referral & $\begin{array}{l}\text { Regional } \\
\text { perinatal } \\
\text { centre } \\
(n=333)\end{array}$ & $\begin{array}{l}\text { Neonatal } \\
\text { intensive } \\
\text { care unit } \\
(n=261)\end{array}$ & $\begin{array}{c}\text { Special care } \\
\text { baby unit } \\
(\mathbf{n}=71)\end{array}$ \\
\hline \multicolumn{4}{|l|}{ Prenatally: } \\
\hline Preterm labour & 88 & 62 & 28 \\
\hline Pre-eclampsia & 47 & 14 & 8 \\
\hline Rhesus isoimmunisation & 23 & & 3 \\
\hline Placenta praevia & 14 & 6 & 4 \\
\hline Abruption of placenta & 5 & 4 & \\
\hline Retarded growth & 4 & 1 & \\
\hline Other & 14 & 6 & 1 \\
\hline Total (\%) & $195(59)$ & $93(36)$ & $44(62)$ \\
\hline \multicolumn{4}{|l|}{ Neonatally: } \\
\hline Respiratory distress syndrome & 79 & 112 & 21 \\
\hline Asphyxia at birth & 26 & 21 & 2 \\
\hline Aspiration of meconium & 6 & 11 & 2 \\
\hline Infection & 6 & 11 & 1 \\
\hline Jaundice & 2 & 1 & \\
\hline Congenital abnormality & 2 & 7 & 1 \\
\hline Surgery & 2 & 1 & \\
\hline Special investigation & 8 & 1 & \\
\hline Other & 7 & 3 & \\
\hline Total (\%) & $138(41)$ & $168(64)$ & $27(38)$ \\
\hline
\end{tabular}

TABLE II-Comparison of obstetric and perinatal variables and mortality in babies for whom transfer to regional perinatal centre was requested according to whether babies were treated at centre, in neonatal intensive care unit, or in special care baby unit

\begin{tabular}{lcccc}
\hline & $\begin{array}{c}\text { Regional } \\
\text { perinatal centre } \\
(\mathbf{n}=333)\end{array}$ & $\begin{array}{c}\text { Neonatal } \\
\text { intensive care } \\
\text { unit } \\
(\mathrm{n}=261)\end{array}$ & $\begin{array}{c}\text { Special care } \\
\text { baby unit } \\
(\mathrm{n}=71)\end{array}$ & p Value \\
\hline Mean (SD) birth weight (g) & $1977(940)$ & $2024(954)$ & $2175(990)$ & $0 \cdot 28$ \\
Mean (SD) gestation (weeks) & $33 \cdot 0(4 \cdot 5)$ & $32 \cdot 7(4 \cdot 7)$ & $33 \cdot 5(4 \cdot 4)$ & $0 \cdot 38$ \\
No(\%) male & $190(57)$ & $154(59)$ & $42(59)$ & $0 \cdot 89$ \\
No(\%) with respiratory distress syndrome & $208(62)$ & $196(75)$ & $38(54)$ & $0 \cdot 0003$ \\
No(\%) with 1 minute Apgar score <5 & $116(35)$ & $83(32)$ & $22(31)$ & $0 \cdot 70$ \\
No(\%) with 5 minute Apgar score $<7$ & $81(24)$ & $71(27)$ & $18(25)$ & $0 \cdot 69$ \\
No(\%) multiple pregnancies & $62(19)$ & $40(15)$ & $15(21)$ & $0 \cdot 41$ \\
No(\%) breech presentation & $34(10)$ & $42(16)$ & $10(14)$ & $0 \cdot 10$ \\
No(\%) for whom initial request made prenatally & $195(59)$ & $93(36)$ & $44(62)$ & \\
No(\%) who died & $51(15 \cdot 3)$ & $49(18 \cdot 8)$ & $21(29 \cdot 6)$ & \\
\hline
\end{tabular}

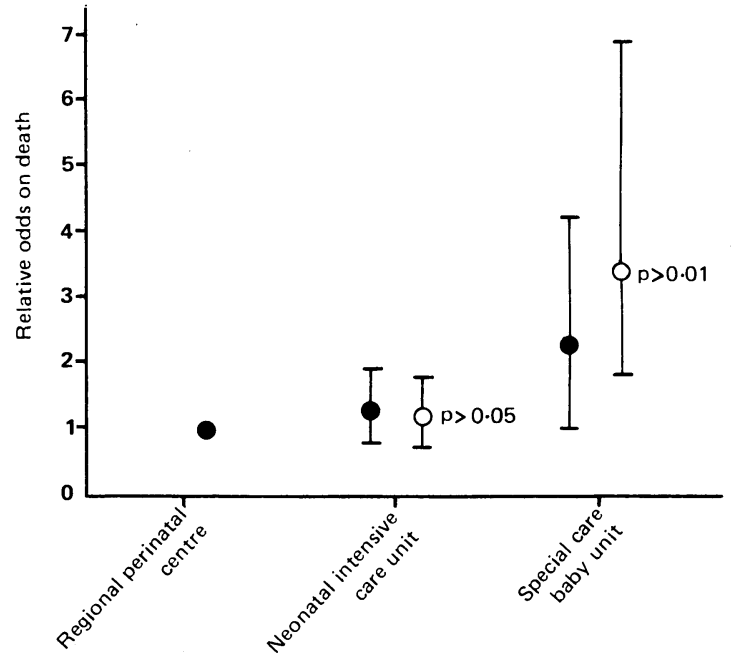

Odds on death in babies for whom transfer to regional perinatal centre was refused and who were admitted to neonatal intensive care units and special care baby units relative to those admitted to centre. Closed. circles represent unadjusted odds; open circles represent odds adjusted for both weight, gestation, presentation (cephalic or breech), presence of respiratory distress syndrome, and type of initial request for transfer (prenatal or postnatal). Bars represent $95 \%$ confidence intervals

problems were the commonest indications for requesting transfer of neonates (table I).

Fifty one of the 333 babies admitted to the regional centre died (15\%) compared with 70 of the 332 babies refused admission $(21 \%)$. The $\chi^{2}$ analysis showed no significant difference in mortality between the two groups $\left(\chi^{2}=3 \cdot 34 ; 0 \cdot 05<p<0 \cdot 10\right)$. Even after adjustment for important covariates with the logistic model the difference was not significant $\left(\chi^{2}=3.07\right.$; $0.05<\mathrm{p}<0 \cdot 10)$. Of the babies who were not admitted to the centre and who received intensive care in smaller units, $49(19 \%)$ died. Of those who were not admitted to the centre and received only special care, $21(30 \%)$ died; 12 of these 21 babies weighed more than $1500 \mathrm{~g}$ and only one died because of a congenital abnormality.

Table II compares the characteristics of the babies in the three study groups. Further analysis indicated that quadratic as well as linear terms in birth weight and gestation were required in the logistic model and that the presence of the respiratory distress syndrome, breech presentation, and the type of initial transfer request (prenatal or postnatal) were the most likely confounding variables. After adjustment for these variables the odds on death relative to babies admitted to the centre were slightly higher for babies refused admission but transferred to other, smaller neonatal intensive care units $(1 \cdot 2 \% ; 95 \%$ confidence interval $0 \cdot 7$ to $1.9 ; \mathrm{p}>0.05)$. For the babies who were refused intensive care and received only special care the relative odds on death were $3 \cdot 5(1 \cdot 7$ to $7 \cdot 0)$, indicating a significantly higher mortality $(\mathrm{p}<0.001)$ (fig 1 ).

A subgroup analysis was performed on babies who weighed less than $1500 \mathrm{~g}$ and who were born at $\leqslant 32$ weeks' gestation. Relative to babies admitted to the centre the odds on death were similar for babies refused admission but admitted to other, smaller neonatal intensive care units $(1 \cdot 0 ; 0 \cdot 5$ to $2 \cdot 1)$. In the babies who were refused intensive care and received only special care, the relative odds on death were significantly higher $(8 \cdot 4 ; 2 \cdot 5$ to $28 \cdot 1)$.

\section{Discussion}

Only two previous studies (both from the same hospital) have compared the outcome in babies refused admission with those accepted for neonatal intensive care. ${ }^{67}$ These studies concluded that the babies refused admission had a poorer outcome, but each study had drawbacks in design. The first study considered only 
one year of referrals and hence the numbers were small. ${ }^{6}$ The second study covered three years and included larger numbers of babies, but only referrals made postnatally were considered. In both studies no account was taken of confounding variables that could influence neonatal mortality.

Our study of referrals to the regional perinatal centre included hospitals from all over Northern Ireland. Cross regional referrals are not made in Northern Ireland and it proved relatively easy to trace most $(98.3 \%)$ of the obstetric and neonatal records during the three years. We also considered babies who were referred prenatally, and the only criterion for refusal was unavailability of an intensive care cot for neonates at the centre. As this was not a randomised study, we adjusted for confounding variables in comparing outcome in the groups.

Of babies initially refused admission to the centre, most $(78.6 \%)$ were subsequently accepted into other neonatal intensive care units within Northern Ireland. There was no significant difference in outcome for babies managed in these units compared with those managed in the centre. In many cases, however, there was a considerable delay before babies refused admission to the centre could be given intensive care, and their long term outcome remains uncertain. We have shown previously that the incidence of handicap is significantly higher in babies referred for intensive care after birth compared with those accepted prenatally. " A delay in starting intensive care may therefore be important. Those babies who did not receive intensive care and remained in special care baby units had a greater than threefold increase in their odds on dying. In addition, survivors from these hospitals could be expected to have a higher incidence of handicap than those sent for intensive care, although follow up studies are needed to confirm this.

There was some imbalance in the indications for prenatal referral, particularly in the number of cases of pre-eclampsia and rhesus isoimmunisation. This reflects clinical practice in that delivery of mothers with these conditions can often be delayed until an intensive care cot becomes available.

The number of babies who needed intensive care but were refused admission may be an underestimate as obstetricians and paediatricians at the hospitals that refer such babies may have known that intensive care cots were not available at the centre and therefore did not request transfer. Examination of mortality related to birth weight in individual hospitals might clarify this further.

Our study confirmed the benefits of neonatal intensive care and its particular value in improving the survival of babies of low birth weight. Short term survival seemed to be similar in smaller neonatal intensive care units and the regional perinatal centre, but we did not look at long term outcome and handicap. Further studies are needed to determine the influence of delay in starting intensive care on short term outcome and handicap. Clearly, in Northern Ireland, as in other parts of the United Kingdom, ${ }^{5}$ not enough neonatal intensive care cots are provided and the deficiency should be remedied as soon as possible.

1 Blake AM, Pollitzer MJ, Reynolds EOR. Referral of mothers and infants for intensive care. Br Med F 1979;ii:414-36.

2 Lobb MO, Morgan MEI, Bond AP, Cooke RWI. Transfer before delivery on Merseyside: an analysis of the first 140 patients. $\mathrm{Br} \mathcal{F}$ Obstet Gynaecol 1983;90:338-41.

3 Powell TG, Pharoah POD. Regional neonatal intensive care: bias and benefit. BrMed J 1987;295:690-2.

4 Cooke RW. Where should low birthweight babies be born? Br Med $\mathcal{f}$ 1986;293:974-5.

5 Royal College of Physicians of London. Medical cure of the newborn in England and Wales. London: RCP, 1988. (Report No 0-900596-79-1.)

6 Sims DG, Wynn J, Chiswick ML. Outcome for newborn babies declined admission to a regional neonatal intensive care unit. Arch Dis Child admission to

7 Roper HP. Chiswick ML, Sims DG. Referrals to a regional neonatal intensive care unit. Arch Dis Child 1988:63:403-7.

8 Cox DR. The analysis of hinary data. London: Methuen, 1970

9 Patterson CC, Halliday HL. Prediction of outcome after delivery for the very low birthweight $(\leqslant 1500 \mathrm{~g})$ infant. Paediatric and Perinatal Epidemiolog $1982: 2: 221-8$.

10 Halliday HL, Patterson CC, McClure BG, Reid MMcC. Where should low weight habies be born? Br Med f 1986;293:1437.

(Accepted 6 fuly 1989)

\title{
Survey of colourings and preservatives in drugs
}

\author{
I Pollock, E Young, M Stoneham, N Slater, J D Wilkinson, J O Warner
}

Heart and Lung Institute, Brompton Hospital,

London

I Pollock, MRCP, research registrar

J O Warner, FRCP, consultant paediatric chest physician

\section{Department of}

Dermatology, Wycombe

General Hospital,

Buckinghamshire

E Young, MRCP, senior registrar in dermatology M Stoneham MRCGP, research assistant in dermatology

N Slater, computer technician

J D Wilkinson, FRCP,

consultant dermatologist

Correspondence to:

Dr I Pollock, Department of

Child Health, St George's

Hospital, London

SW 17 0RE.

Br.Med. I 1989;299:649-51

\section{Abstract}

Objective-To assess the prevalence of colourings and preservatives in drug formulations in the United Kingdom.

Design-Postal survey.

Participants-All pharmaceutical manufacturers in the United Kingdom were requested to supply data on drug formulations with particular regard to the content of colourings and preservatives.

Main outcome measure-Prevalence in proprietary drugs of colourings or preservatives, or both, that have been implicated in adverse reactions. Computation of a list of formulations of bronchodilators, antihistamines, and antibiotics that are free of such additives.

Results-A total of 118 out of 120 pharmaceutical companies supplied the data requested. In all, 2204 drug formulations were analysed and found to contain 419 different additives, of which .52 were colourings and preservatives that have been implicated in adverse reactions; 930 formulations contained such an additive. Tartrazine was the fourth most commonly occurring colouring, being present in 124 drug formulations.

Conclusion-Many drugs contain additives that help to identify them and prolong their shelf life but are implicated in adverse reactions in some people. Some form of labelling of drug additives would enable these people to avoid drugs containing such additives.

\section{Introduction}

Many additives are used in drugs by the pharmaceutical industry for a variety of reasons, including improved identification and stability. Although adverse reactions to drugs have been reported and investigated for many years, adverse reactions to drug additives such as colourings and preservatives have been reported only over the past 30 years. ${ }^{1-4}$ Some of the colourings and preservatives that are added to drugs are also added to foods, and various adverse reactions have been attributed to them, although the validity of reports has been questioned. ${ }^{5}$ Colourings, however, have been reported to cause urticaria ${ }^{6-10}$ and preservatives, such as sulphites, to cause asthma. ${ }^{11 \cdot 13}$ There is little evidence that food or drug additives cause hyperactivity in children ${ }^{14}$ despite popular perceptions and the results of several studies. ${ }^{15-18}$

The prevalence of adverse reactions to food additives 